\section{Extending Our Reach-Will Telemedicine Get Us There?}

We all know there is an oncology workforce shortage that threatens to loom larger in the coming decades. Our population is aging more successfully and, for many malignancies, the incidence is rising. Of course, fewer people are dying, but that is because they receive state-of-the-art care. Because fewer people are dying there are more survivors who experience lingering effects of their disease or treatments and have other medical challenges.

I've written before about this problem and suggested that at least one solution is the increased adoption of physician extenders-nurse practitioners and physician assistants who can help our patients navigate the treacherous paths of treatment and recovery. But what about telemedicine? Can telemedicine get us one step further?

I will admit up-front that I prefer face-to-face meetings in person. I've never adopted "FaceTime" to interact with my family, and I treasure the opportunity to hold a hand or give a hug when it's needed. But I have to admit that my patients have a daunting challenge. To see me, they usually have to fight gridlock traffic in a confusing city, pay exorbitant parking costs, and wait in an uncomfortable waiting room because I am always behind schedule. Wouldn't a "tele-visit" be a lot easier for them? And maybe even for me. Theoretically, I could do tele-visits from home, right?

I acknowledge that I can tell a lot about how a person is doing just from observation and a few simple questions. Detailed, hands-on physical examinations are becoming less relevant in oncology with the increased use of imaging and other sophisticated diagnostics. Reimbursement for face time with a patient has improved, so there may be a way to make this economically feasible. But my being able to work from my home computer or my office doesn't make the other costs associated with a visit go away. After all, patients still need to have their vitals taken and medication list updated. And of course, there may be a need for laboratory work and imaging. In medical oncology, what about infusion care? Where does all that get done?

For academic centers, and indeed for hospital-based oncology practices, I see this method working in conjunction with a network of distant clinical sites that offer needed ancillary services. I'm struggling to see the benefit for community oncologists who may not have the luxury of a network. But I do see an advantage for procedurebased specialties in many disciplines. Having a reimbursable system for assessing the need for a procedure makes sense, reserving the "hands-on" time for the actual procedure.

I think telemedicine will gain traction. It has a lot of inherent value for all involved. For my younger colleagues, it will be more natural. Many already use video or telecommunication in their personal lives, such as visiting with their kids at daycare or spying on their pets left at home! As for me, I will just have to get used to dressing up and applying my makeup before I start my day from home. After all, someone may be watching me!

What do you think? Please e-mail correspondence (include contact information) to JNCCN@nccn.org or log into www.editiorialmanager.com/JNCCN to submit a Letter to the Editor.

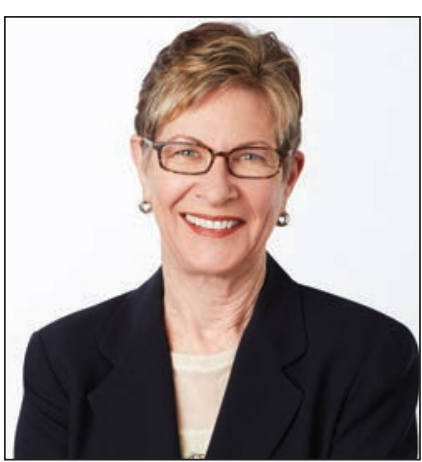

Margaret Tempero, MD

Margaret Tempero, MD, is a Professor of Medicine and Director of the UCSF Pancreas Center and editor-in-chief of JNCCN. Her research career has focused on pancreatic ductal adenocarcinoma, especially in the area of investigational therapeutics. Dr. Tempero has served on the ASCO Board of Directors and as ASCO President. She currently serves on the ASCO Conquer Cancer Foundation Board. She codirected the AACR/ASCO Methods in Clinical Cancer Research and taught this course and similar courses in Europe and Australia. She was founding Chair of the $\mathrm{NCl}$ Clinical Oncology Study Section and served as a member and Chair of the NCl Board of Scientific Counselors Subcommittee $A$. She is a member of the Scientific Steering Committee and Chair of the Clinical and Translational Study Section for the Cancer Prevention \& Research Institute of Texas. She is or has been on the Scientific Advisory Boards of the Lustgarten Foundation, the Pancreatic Cancer Action Network, the $V$ Foundation, The Alberta Canada Cancer Board, and the EORTC. She served as a member of the Oncology Drug Advisory Committee for the FDA. She has served as Deputy Director and Interim Director for the UNMC Eppley Cancer Center. She is Chief Emeritus of the Division of Medical Oncology at UCSF and served as the founding Deputy Director and Director of Research Programs at the UCSF Helen Diller Family Comprehensive Cancer Center.

doi: $10.6004 /$ jnccn.2018.0008

The ideas and viewpoints expressed in this editorial are those of the author and do not necessarily represent any policy, position, or program of NCCN. 